\title{
Safety and Effectiveness of a Perturbation-based Neuromuscular Training Program on Dynamic Balance in Adolescent Females: A Randomized Controlled Trial
}

\author{
Alison Bulow, CAT(C), PhD ${ }^{1}$, Judith E Anderson, PhD², Jeff R S Leiter, PhD ${ }^{1}$, Peter B MacDonald, MD, FRCSC ${ }^{3}$, Jason D \\ Peeler, $\mathrm{CAT}(\mathrm{C}), \mathrm{PhD}^{4}$ a \\ ${ }^{1}$ Human Anatomy \& Cell Science, University of Manitoba, ${ }^{2}$ Biological Sciences, University of Manitoba, ${ }^{3}$ Surgery, University of Manitoba; Pan Am \\ Clinic, ${ }^{4}$ Human Anatomy \& Cell Science, University of Manitoba; Pan Am Clinic \\ Keywords: movement system, functional testing, anterior cruciate ligament \\ https://doi.org/10.26603/001c.25685
}

\section{International Journal of Sports Physical Therapy}

\begin{abstract}
Background
Adolescent females are at much greater risk for ACL injury than their male counterparts when participating in the same sports. Preventative and pre-operative rehabilitation neuromuscular (NM) exercise programs are often recommended to improve knee function and reduce injury rates. The effectiveness of perturbation-based NM training program has been established in an adult population but has yet to be investigated in the at-risk adolescent female population.
\end{abstract}

\section{Purpose}

To determine the effectiveness of a perturbation-based NM exercise program in a group of physically active adolescent females.

\section{Study Design}

Prospective randomized trial.

\section{Methods}

Twenty-four healthy and an exploratory group of 10 ACL-injured females (ages 12-18) were equally randomized into a perturbation-based NM training or control group and evaluated before and after a five-week intervention period. The primary outcome of dynamic balance was measured using the Y-Balance test (YBT); secondary outcome measures included lower limb strength, proprioception, and flexibility.

\section{Results}

The perturbation-based NM training intervention was safely completed by all participants but had no significant effect on YBT scoring, lower limb strength, proprioception or flexibility in either the healthy or ACL-injured groups.

\section{Conclusions}

Perturbation-based NM training is safe, but may offer little preventative benefit for healthy or pre-operative rehabilitation benefit for ACL-injured adolescent females. Future research should examine whether the effectiveness of perturbation-based NM training is influenced by the length of the training intervention, training intensity, or when it is combined with other forms of prophylactic or pre-surgical rehabilitation frequently used with at-risk adolescent females who regularly participate in sport.

\footnotetext{
a Corresponding author: 


\section{Level of Evidence}

Level 3.

\section{INTRODUCTION}

Rupture of the anterior cruciate ligament (ACL) is one of the most common knee injuries, with an estimated 250,000 ACL ruptures documented per year in North America. ${ }^{1}$ It is also the most commonly injured knee ligament in a pediatric population, 2,3 with its incidence growing fastest in physically active adolescents (14 - 18 years old) participating in high school sports. ${ }^{4}$ While an ACL injury is a significant risk for both sexes, adolescent females have a 1.6-fold greater rate of ACL injury per athletic exposure than adolescent males participating in the same sports. ${ }^{4,5}$

In North America, the standard of care for young patients following ACL rupture is surgical reconstruction.6,7 Early surgical repair is especially favored for adolescent patients because it helps to restore joint stability, reduces the incidence of secondary joint injury, and promotes return to pre-injury levels of physical activity. ${ }^{8}$ However, skeletal immaturity ${ }^{7,9}$ and long surgical wait times ${ }^{10}$ can result in significant delays in the injury-to-surgery time line. The average injury-to-surgery wait time following ACL injury within a local Canadian regional health authority has been documented to be as high as 438 days. ${ }^{10}$ As a result, pre-operative exercise programs are frequently prescribed for patients awaiting ACL reconstructive surgery, ${ }^{11,12}$ as they are thought to help re-establish the normal kinetic and kinematic function of the affected joint. Superior functional outcomes and higher return-to-sport rates have been reported for adult patients who participated in rehabilitation programs that included perturbation-based neuromuscular training as part of a pre-operative treatment regimen. ${ }^{13}$

Neuromuscular (NM) training is designed to improve dynamic joint stability, generate fast and optimal muscle activation, and decrease joint forces. It forms a critical aspect of injury prevention exercise programs that are designed to reduce the costs and morbidity associated with ACL injury in young athletes. ${ }^{14}$ In addition to reducing the rate of ACL ruptures in female adolescents by approximately $50 \%,{ }^{15-18}$ research suggests that NM training during early adolescence can improve lower extremity performance ${ }^{19,20}$ and dynamic balance. ${ }^{21-24}$ While the specific exercises included in an NM training regime can vary greatly, NM programs typically include some form of plyometric single-leg hopping, jumping, pivoting, or cutting maneuvers that are considered unsafe or impractical for use with an ACL-injured individual. ${ }^{15-20,25-29}$

Perturbation-based NM training regimens are designed to be safe and effective for ACL-injured patients as part of a pre-operative exercise program. ${ }^{30}$ They typically include exercises that require the patient to maintain their balance on a support surface while a clinician deliberately perturbs (i.e., manipulates) the support system. ${ }^{31}$ Research targeting an ACL-injured adult population indicates that perturbation-based NM training is effective for improving knee joint kinematics, gait patterns, subjective functional outcomes and return-to-sport rates. ${ }^{13,31-38}$ Unfortunately, the safety and effectiveness of a perturbation-based NM train- ing regime in an at-risk adolescent female population is unreported in the literature.

The purpose of this investigation was to determine the effectiveness of a perturbation-based NM exercise program in a group of physically active adolescent females. The primary outcome measure was dynamic balance, while lower limb strength, proprioception, and flexibility were outcome measures of secondary interest. Program safety was assessed by evaluating the number and severity of injuries sustained by subjects. The authors hypothesized that completion of a perturbation-based NM exercise program would improve 1) dynamic balance and 2) lower extremity strength, proprioception and flexibility in physically active adolescent females.

\section{METHODS}

\section{PARTICIPANTS}

Following institutional ethics approval (H2014:302), healthy and ACL-injured physically active adolescent females were recruited from the community. Inclusion criteria stated that healthy volunteers were required to be female, 12-18 years of age, with no history of any lower limb injury or concussions in the past 6 months. A group of subjects awaiting ACL surgical repair were recruited from a community-based orthopaedic clinic to participate in this clinical study following the same inclusion criteria (Figure 1). Subjects were evaluated clinically by an orthopaedic surgeon and the diagnosis of an isolated ACL rupture (without secondary injury to menisci or chondral surfaces) was confirmed via magnetic resonance imaging. Participants were excluded if they were unable to attend either the testing or training sessions or if they failed an established standardized screening protocol ${ }^{30}$ at the beginning of the study. A participant was scored as a "failure" and excluded from study participation if they presented with knee joint effusion, were unable to fully flex and extend the knee joint though a full range of motion, had quadriceps lag with an active straight-leg raise, had isometric quadriceps strength less than $75 \%$ of the unaffected leg measured via manual muscle testing or were unable to perform 10 consecutive single-legged hops pain free. ${ }^{30}$

\section{TESTING PROTOCOL}

Prior to participation, informed consent was obtained from all girls and their parents. Anthropometric data including height, weight, and body mass index (BMI) were recorded. Bilateral knee joint laxity was evaluated using the KT-1000 (MEDmetric Corp.; San Diego, CA). ${ }^{39}$ Demographic information, including age, maturation status determined by using the self-reported pubertal maturation observational scale (PMOS), ${ }^{40}$ leg dominance (determined by leg preference for kicking a ball), and type of sport participation were collected. Participants were then equally randomized into 2 groups (perturbation-based NM training or control) using pre-coded envelopes that were assigned to each partic- 
ipant. Baseline measurements for dynamic balance, lower limb strength, proprioception, and flexibility were completed on all participants. Participants randomized to the intervention group completed a 5-week perturbation-based NM training regime while the participants randomized into the control group were instructed to continue with their normal activities. All participants returned for follow-up evaluation.

\section{DYNAMIC BALANCE MEASUREMENT}

To measure dynamic balance, the Y-Balance Test (YBT) (Move2Perform; Evansville, IL) was completed according to previously described protocols. ${ }^{41,42}$ The distance from the YBT apex of the most proximal edge of the reach indicator was recorded while participants performed movement in three directions: anterior (ANT), posteromedial (PM) and posterolateral (PL). The average of 3 successful trails for each reach direction was used for analysis. All reach distances were normalized as a percentage of each participant's stance-limb length (\%LL), measured from the anterior superior iliac spine to the most distal aspect of the ipsilateral medial malleolus in a supine, lying position. ${ }^{43}$

\section{LOWER LIMB STRENGTH EVALUATION}

Hand-held dynamometry (HHD) is a valid, reliable measure of isometric muscle strength in adolescents ${ }^{44}$ and an ideal test method for use when evaluating lower extremity strength in a clinical setting. ${ }^{44,45}$ The "make-test" method was used because it is preferred for use with adolescents: the examiner held the dynamometric instrument (Chatillon DFX II Series; Largo, FL) in a stationary position while the subject gradually built resistance for a 5-second push against the dynamometer. ${ }^{44}$ Standardized positions were used to assess strength during knee flexion, knee extension, hip external rotation, hip abduction, and ankle plantar flexion movements. ${ }^{46}$ Strength scores for each movement were determined by calculating the average of three HHD measurements for each movement. Strength scores for each subject were then expressed as HHD force $(\mathrm{N})$ relative to body weight $(\mathrm{kg})$.

\section{KNEE PROPRIOCEPTION EVALUATION}

Joint-position sense (JPS) - the awareness of limb position in three dimensions - is a common proprioceptive test routinely used during weight bearing (WB) activity to provide a functional evaluation ${ }^{47}$ with greater clinical relevance ${ }^{48}$ for conditions such as ACL instability. ${ }^{49}$ Using previously described methodologies, ${ }^{47,48}$ the WB-JPS for each participant was assessed. Briefly, with eyes closed and while maintaining a unilateral stance, each subject was instructed to slowly flex the knee of the WB limb and to stop at approximately 30 degrees of flexion - the test angle (TA). An electro-goniometer (Acumar Dual Inclinometer ACU0002, Lafayette Instrument Company; Lafayette, IN) was then used to confirm the exact knee-joint angle. The TA was held for approximately 5 seconds, after which the subject was directed to return to a position of full knee extension and bilateral stance. The subject was then asked to reproduce

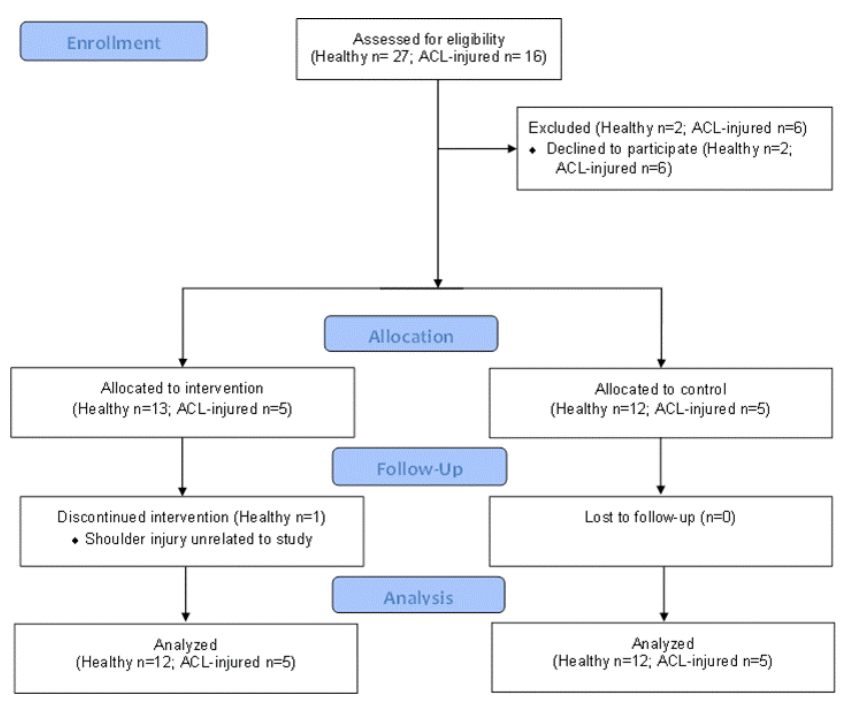

Figure 1. CONSORT study flow diagram.

the same amount of unilateral knee flexion - response angle (RA). Absolute angular error (AAE) is the absolute arithmetic difference between the TA and RA scores. All subjects repeated the WB-JPS test three times, with the average AAE for each limb being used for analysis.

\section{LOWER EXTREMITY FLEXIBILITY EVALUATION}

Hamstring and calf muscle flexibility were evaluated using joint-specific tests executed according to previously established protocols. ${ }^{50-52}$ A standing toe-touch test was used to assess hamstring flexibility. ${ }^{51}$ Briefly, subjects stood on a step-stool with their feet hip-width apart and were instructed to keep their knees, arms and fingers straight while they bent forward as far as possible. The maximum reach position (held for a minimum of 6 seconds) was measured to the nearest $0.5 \mathrm{~cm}$. The average of three trials was used for analysis. ${ }^{51}$ Calf muscle flexibility was determined using the weight-bearing lunge test (WBLT). ${ }^{50}$ Briefly, while in a standing position facing a wall, subjects were instructed to keep their test heel on the floor while flexing their knee to touch the wall in front of them. The maximum reach position was determined by measuring the distance from the great toe to the wall (measured to the nearest $0.5 \mathrm{~cm}$ ) while maintaining heel and knee contact. After three practice trials, subjects completed three test trials, the average of which was used for analysis. ${ }^{50}$

\section{PERTURBATION-BASED NM EXERCISE REGIME}

Participants randomized to the perturbation-based NM training group completed two supervised training sessions per week for five consecutive weeks (for a total of 10 sessions). This validated training program $11,31-34,53-57$ was administered according to a previously established procedure (Appendix). ${ }^{30}$ In brief, a series of destabilizing perturbations were applied during either unilateral or bilateral stance on each of three unstable surfaces (rockerboard, rollerboard and rollerboard/platform). ${ }^{30}$ Over the five-week training regime, application of the destabilizing force pro- 
gressed in a standardized manner from an informed unilateral direction (slow and low in magnitude), to an unexpected, rapid application of destabilizing forces in random directions with sport-related distractions (catching and throwing a ball at the same time performing balance activity).

\section{STATISTICAL ANALYSIS}

A power analysis based on scoring from previous investigations that examined dynamic balance in a healthy group of recreationally active adults indicated that a total of 11 subjects per group would be required for the current investigation. ${ }^{58,59}$ Following the recommendation of a previous report, 60 the dominant limb of all healthy participants and the affected limb of the ACL-injured participants was used for analysis. SPSS for Windows 24.0 (SPSS Inc.; Chicago, IL) was used for analysis. One-way analysis of variance (ANOVA) was used to test the differences in baseline demographic and anthropometric data between perturbation and control groups for each of healthy and ACL-injured groups. Two-way ANOVAs were used to compare baseline and follow-up scoring on dynamic balance, proprioception, flexibility, and strength. A post hoc Bonferroni correction of $p \leqslant 0.008$ was set to determine statistical significance. A Fisher's exact test was used to examine the relationship between the group (control or perturbation training) and clinically significant improvements in each YBT reach direction. The level of statistical significance was set at $p \leqslant$ 0.05 while a clinically significant improvement was classified as greater than $8.54 \%, 13.50 \%$ and $13.70 \%$ for the ANT, $\mathrm{PM}$ and PL reach directions, respectively. ${ }^{61}$

\section{RESULTS}

Table 1 provides descriptive data for participant demographics and anthropometry. Baseline data indicated that there were no significant differences between control and perturbation groups on the demographic and anthropometric data between groups. However, the ACL-injured control group was significantly older than both healthy-perturbation and healthy-control groups. Knee joint laxity for both the ACL-injured control and perturbation groups was also significantly greater than both of the healthy groups - as would be expected. For ACL-injured participants, the mean time from injury to the baseline examination was 143 days (range: 24-365). Over the duration of the study, there were no significant changes in weight, or BMI for any of the groups. Results suggested that participants in each group were predominantly post-pubertal adolescents who were right leg dominant and participated in a variety of sporting activities.

All participants completed both testing sessions and the mean time from the initial assessment to follow-up assessment was 41 days (range: 30-47). All subjects (healthy and ACL-injured) randomized to the perturbation group safely completed the training program without any incidence of pain, swelling or knee instability. The training program included 10 sessions; the mean number of completed sessions was nine (range: 7-10). On average, each training session was completed in approximately 30 minutes and the 10

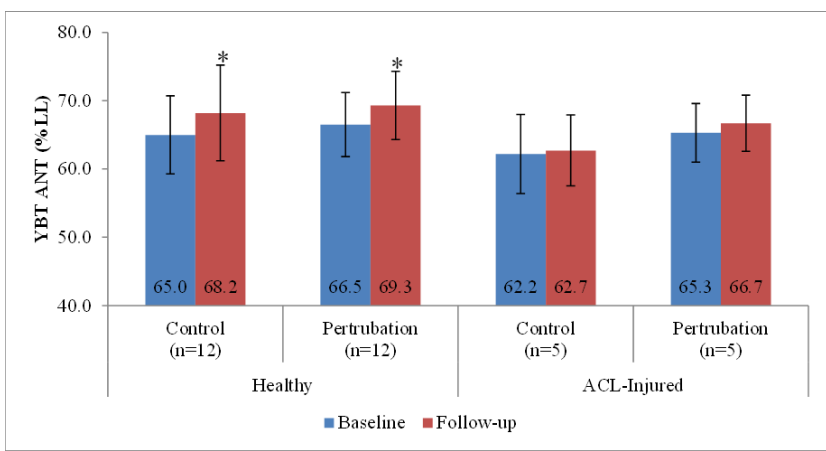

Figure 2. Performance changes on the YBT Anterior (ANT) reach direction for healthy and ACL-injured subjects (mean $\pm \mathrm{SD})$.

Time effect: ${ }^{*} \leqslant 0.008$ (Bonferroni correction).

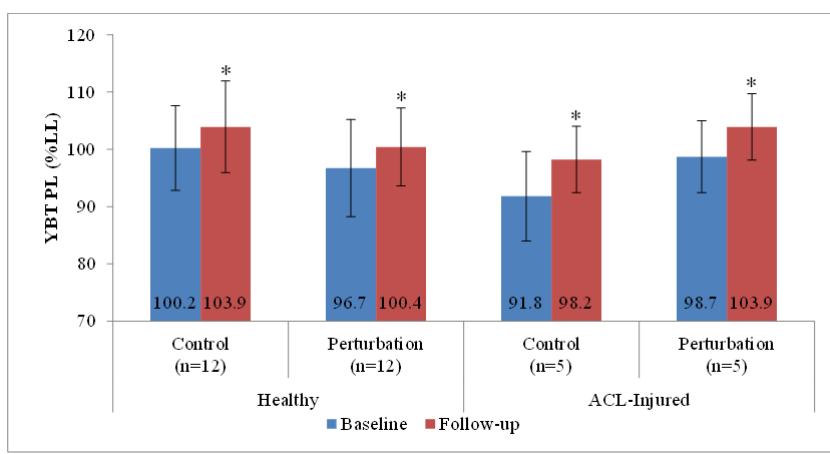

Figure 3. Performance changes on the YBT Posterolateral (PL) reach direction for healthy and ACL-injured subjects (mean $\pm \mathrm{SD}$ ).

Time effect: $p \leqslant 0.008$ (Bonferroni correction).

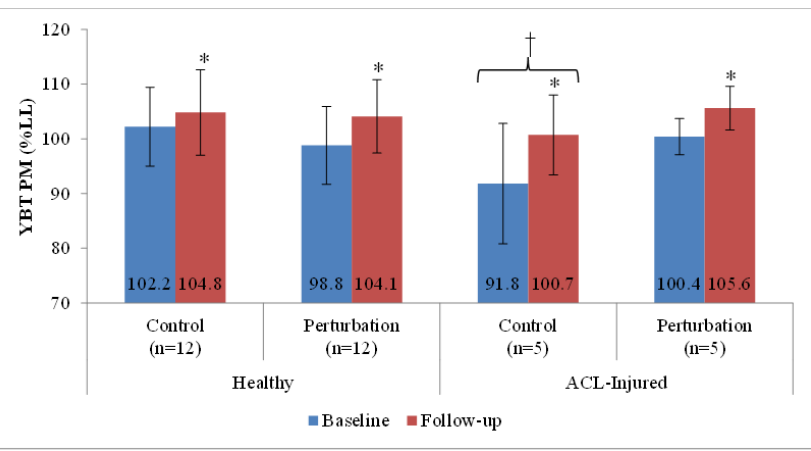

Figure 4. Performance changes on the YBT Posteromedial (PM) reach direction for healthy and ACL-injured subjects (mean \pm SD).

Time effect: * $p \leqslant 0.008$; Training effect: $\dagger p \leqslant 0.008$ (Bonferroni correction).

training sessions took place over an average of 31 days (range: 21-35). No subjects randomized to the training group reported any incidence of knee joint pain, swelling or instability while participating in the training program exercises or at the follow-up assessment.

Comparisons of baseline and follow-up test scores for the YBT are presented in Figures 2 through 4 . For the ANT 
Table 1. Demographic and anthropometric information for all subjects, reported as mean \pm SD, (95\% confidence interval).

\begin{tabular}{|c|c|c|c|c|}
\hline & \multicolumn{2}{|c|}{ Healthy $(n=24)$} & \multicolumn{2}{|c|}{ ACL-injured $(n=10)$} \\
\hline & $\begin{array}{c}\text { Control } \\
(n=12)\end{array}$ & $\begin{array}{c}\text { Perturbation } \\
(n=12)\end{array}$ & Control $(n=5)$ & $\begin{array}{c}\text { Perturbation } \\
(n=5)\end{array}$ \\
\hline Age (years) & $\begin{array}{c}13.9 \pm 1.1 \\
(13.2,14.6)\end{array}$ & $\begin{array}{c}14.3 \pm 1.5 \\
(13.3,15.2)\end{array}$ & $\begin{array}{c}16.9 \pm 0.9^{*} \\
(15.8,18.0)\end{array}$ & $\begin{array}{c}15.7 \pm 2.0 \\
(13.2,18.2)\end{array}$ \\
\hline Height (cm) & $\begin{array}{c}161.8 \pm 6.2 \\
(157.9,165.7)\end{array}$ & $\begin{array}{c}164.5 \pm 5.5 \\
(161.0,168.0)\end{array}$ & $\begin{array}{c}166.4 \pm 6.1 \\
(158.8,174.0)\end{array}$ & $\begin{array}{c}164.5 \pm 6.8 \\
(156.1,172.9)\end{array}$ \\
\hline Weight (kg) & $\begin{array}{l}54.3 \pm 10.8 \\
(47.4,61.2)\end{array}$ & $\begin{array}{l}63.3 \pm 17.7 \\
(52.0,74.5)\end{array}$ & $\begin{array}{l}63.1 \pm 16.9 \\
(42.1,84.1)\end{array}$ & $\begin{array}{l}72.9 \pm 10.3 \\
(60.1,85.7)\end{array}$ \\
\hline BMI (kg/m²) & $\begin{array}{c}20.6 \pm 3.2 \\
(18.6,22.6)\end{array}$ & $\begin{array}{c}23.3 \pm 5.4 \\
(19.9,26.7)\end{array}$ & $\begin{array}{c}22.6 \pm 4.9 \\
(16.5,28.7)\end{array}$ & $\begin{array}{c}26.9 \pm 3.4 \\
(22.7,31.1)\end{array}$ \\
\hline Knee Laxity Difference (mm) & $\begin{array}{l}1.5 \pm 1.1 \\
(0.8,2.2)\end{array}$ & $\begin{array}{l}1.5 \pm 1.0 \\
(0.8,2.1)\end{array}$ & $\begin{array}{c}5.1 \pm 3.7^{\dagger} \\
(0.5,9.7)\end{array}$ & $\begin{array}{l}5.0 \pm 2.6^{\ddagger} \\
(1.8,8.2)\end{array}$ \\
\hline Time since injury (months) & - & - & $\begin{array}{l}3.6 \pm 2.1 \\
(1.0,6.2)\end{array}$ & $\begin{array}{c}5.9 \pm 3.7 \\
(1.3,10.5)\end{array}$ \\
\hline Leg Dominance - Right, $\mathrm{n}$ & 11 & 10 & 4 & 5 \\
\hline \multicolumn{5}{|l|}{ Developmental status, $\mathrm{n}$} \\
\hline Pre-pubertal & 2 & 1 & 0 & 0 \\
\hline Mid-pubertal & 3 & 2 & 2 & 1 \\
\hline Post-pubertal & 7 & 9 & 3 & 4 \\
\hline \multicolumn{5}{|l|}{ Sport (n) } \\
\hline Basketball & - & 1 & 1 & 2 \\
\hline Badminton & 1 & - & - & - \\
\hline Baton & 1 & 2 & 1 & - \\
\hline Dance & 2 & 2 & - & - \\
\hline Cross country running & - & 1 & - & - \\
\hline Gymnastics & 1 & 1 & - & - \\
\hline Hockey/Ringette & 4 & 1 & 1 & - \\
\hline Rugby & - & - & 1 & - \\
\hline Soccer & 1 & 1 & - & 1 \\
\hline Softball & 1 & - & - & - \\
\hline Tennis & - & 1 & - & - \\
\hline Volleyball & 1 & 2 & 1 & 2 \\
\hline
\end{tabular}

"Significantly different than the healthy control $(p<0.001)$ and healthy perturbation $(p=0.002)$ †Significantly different than the healthy control $(p=0.006)$ and healthy perturbation $(p=0.005)$ ¥Significantly different than the healthy control $(p=0.001)$ and healthy perturbation $(p=0.001)$

reach direction, follow-up test scores of the healthy participants were significantly larger for both the control and perturbation training groups (time effect: $p \leqslant 0.008$ ), while there were no significant differences between baseline and follow-up scores for either of the ACL-injured groups (Figure 2). The YBT data for PL \& PM reach directions indicated that regardless of group allocation (control or perturbation), follow-up test scores of both the healthy and ACLinjured groups were significantly larger than scoring from baseline testing (time effect: $p \leqslant 0.008$ ) (Figures $\underline{3}$ and $\underline{4}$ ).

The results of the Fisher's exact test for the YBT are presented in Table 2. For both the healthy and ACL-injured subjects, no clinically significant differences $(p>0.05)$ were found between the control and perturbation training groups for any of the reach directions.

Strength measurements for the healthy participants in- dicated a statistically significant improvement in hip abduction strength following completion of the perturbationbased NM training regime; however, the improvement was not clinically significant. ${ }^{44}$ All other changes for both groups were not statistically significant, and data suggested that participation in the perturbation-based NM exercise program had no significant effect on strength scores for both the healthy and ACL-injured participants (Tables $\underline{3}$ and 4).

Finally, proprioception and flexibility measurements indicated that there were no significant differences in scoring when comparing both the control or perturbation groups at baseline or follow-up, or when examining the effect of the perturbation-based NM exercise regime on either the healthy or ACL-injured participants (Tables $\underline{5}$ and $\underline{6}$ ). 
Table 2. Numbers of healthy participants having reached clinically significant* improvements in each Y-balance test (YBT) reach direction.

\begin{tabular}{|ccccccc|}
\hline & $\begin{array}{c}\text { Healthy }(\mathrm{n}=24) \\
\text { Control } \\
\text { (yes/no) }\end{array}$ & $\begin{array}{c}\text { Perturbation } \\
\text { (yes/no) }\end{array}$ & $p$ value & $\begin{array}{c}\text { Control } \\
\text { (yes/no) }\end{array}$ & $\begin{array}{c}\text { ACL-injured }(\mathrm{n}=10) \\
\text { Perturbation } \\
\text { (yes/no) }\end{array}$ & $p$ value \\
\hline ANT & $1 / 11$ & $1 / 11$ & 1.0 & $0 / 5$ & $1 / 4$ & 1.00 \\
PL & $0 / 12$ & $0 / 12$ & - & $1 / 4$ & $0 / 5$ & 1.00 \\
PM & $0 / 12$ & $2 / 10$ & 0.48 & $0 / 5$ & $0 / 5$ & - \\
\hline
\end{tabular}

*Clinically significant improvement was classified as ANT >8.54\%, PM >13.50\% and PL >13.70\%; " $p \leqslant 0.05$

Table 3. Strength measurements for the healthy subjects, reported as mean \pm SD, (95\% confidence interval).

\begin{tabular}{|c|c|c|c|c|c|c|}
\hline & \multicolumn{2}{|c|}{ Control $(n=12)$} & \multicolumn{2}{|c|}{ Perturbation $(n=12)$} & \multicolumn{2}{|c|}{$p$-value ${ }^{a}$} \\
\hline & Initial & Follow-up & Initial & Follow-up & Time & Time $x$ Group \\
\hline Knee Flexion (N/kg) & $\begin{array}{l}3.7 \pm 0.6 \\
(3.3,4.1)\end{array}$ & $\begin{array}{l}3.8 \pm 0.6 \\
(3.4,4.2)\end{array}$ & $\begin{array}{l}2.9 \pm 0.6^{*} \\
(2.5,3.3)\end{array}$ & $\begin{array}{l}3.3 \pm 0.7 \\
(2.9,3.7)\end{array}$ & $0.02^{\dagger}$ & 0.11 \\
\hline Knee Extension (N/kg) & $\begin{array}{l}5.4 \pm 1.3 \\
(5.6,6.2)\end{array}$ & $\begin{array}{l}5.8 \pm 1.2 \\
(5.0,6.6)\end{array}$ & $\begin{array}{l}4.8 \pm 1.1 \\
(4.1,5.5)\end{array}$ & $\begin{array}{l}5.5 \pm 1.3 \\
(4.7,6.3)\end{array}$ & $0.02^{\dagger}$ & 0.52 \\
\hline Hip External Rotation (N/kg) & $\begin{array}{l}2.1 \pm 0.5 \\
(1.8,2.4)\end{array}$ & $\begin{array}{l}2.3 \pm 0.4 \\
(2.0,2.5)\end{array}$ & $\begin{array}{l}1.9 \pm 0.3 \\
(1.7,2.1)\end{array}$ & $\begin{array}{l}2.0 \pm 0.4 \\
(1.7,2.2)\end{array}$ & $0.01^{\dagger}$ & 0.48 \\
\hline Hip Abduction (N/kg) & $\begin{array}{l}2.0 \pm 0.4 \\
(1.7,2.2)\end{array}$ & $\begin{array}{l}1.8 \pm 0.3 \\
(1.6,2.0)\end{array}$ & $\begin{array}{l}1.7 \pm 0.3 \\
(1.5,1.9)\end{array}$ & $\begin{array}{l}1.9 \pm 0.4 \\
(1.6,2.1)\end{array}$ & 0.86 & $<0.01^{\ddagger}$ \\
\hline Ankle Plantarflexion (N/kg) & $\begin{array}{l}5.9 \pm 1.3 \\
(5.1,6.7)\end{array}$ & $\begin{array}{l}5.7 \pm 1.2 \\
(4.9,6.5)\end{array}$ & $\begin{array}{l}5.7 \pm 1.3 \\
(4.9,6.5)\end{array}$ & $\begin{array}{l}5.4 \pm 1.3 \\
(4.6,6.2)\end{array}$ & 0.43 & 0.82 \\
\hline
\end{tabular}

a Findings from multivariate analysis of variance

* Lower than the Control initial $(p=0.003)$ and follow-up $(p=0.002)$ groups.

$\dagger$ Increased from initial to follow-up for all groups

$¥$ Control group decreased and perturbation group increased

Table 4. Strength measurements for the ACL-injured subjects, reported as mean \pm SD, (95\% confidence interval).

\begin{tabular}{|c|c|c|c|c|c|c|}
\hline & \multicolumn{2}{|c|}{ Control $(n=5)$} & \multicolumn{2}{|c|}{ Perturbation $(n=5)$} & \multicolumn{2}{|c|}{$p$-value ${ }^{a}$} \\
\hline & Initial & Follow-up & Initial & Follow-up & Time & Time $\times$ Group \\
\hline Knee Flexion (N/kg) & $\begin{array}{l}3.1 \pm 1.1 \\
(1.7,4.5)\end{array}$ & $\begin{array}{l}3.6 \pm 1.1 \\
(2.2,5.0)\end{array}$ & $\begin{array}{l}2.7 \pm 0.3 \\
(2.3,3.0)\end{array}$ & $\begin{array}{l}3.0 \pm 0.3 \\
(2.6,3.4)\end{array}$ & $<0.01^{*}$ & 0.55 \\
\hline Knee Extension (N/kg) & $\begin{array}{l}5.0 \pm 1.8 \\
(2.8,7.2)\end{array}$ & $\begin{array}{l}5.6 \pm 1.4 \\
(3.9,7.3)\end{array}$ & $\begin{array}{l}4.5 \pm 0.5 \\
(3.9,5.1)\end{array}$ & $\begin{array}{l}4.9 \pm 0.8 \\
(3.9,5.9)\end{array}$ & 0.09 & 0.77 \\
\hline Hip External Rotation (N/kg) & $\begin{array}{l}1.9 \pm 0.7 \\
(1.0,2.8)\end{array}$ & $\begin{array}{l}2.1 \pm 0.7 \\
(1.2,3.0)\end{array}$ & $\begin{array}{l}1.6 \pm 0.2 \\
(1.3,1.8)\end{array}$ & $\begin{array}{l}1.8 \pm 0.3 \\
(1.4,2.2)\end{array}$ & $0.02^{\mathrm{b}}$ & 0.91 \\
\hline Hip Abduction (N/kg) & $\begin{array}{l}1.5 \pm 0.3 \\
(1.1,1.9)\end{array}$ & $\begin{array}{l}1.5 \pm 0.3 \\
(1.1,1.9)\end{array}$ & $\begin{array}{l}1.5 \pm 0.2 \\
(1.2,1.7)\end{array}$ & $\begin{array}{l}1.6 \pm 0.3 \\
(1.2,2.0)\end{array}$ & 0.37 & 0.44 \\
\hline Ankle Plantarflexion (N/kg) & $\begin{array}{l}5.4 \pm 1.4 \\
(3.7,7.1)\end{array}$ & $\begin{array}{l}5.6 \pm 1.1 \\
(4.2,7.0)\end{array}$ & $\begin{array}{l}4.8 \pm 1.0 \\
(3.6,6.0)\end{array}$ & $\begin{array}{l}4.9 \pm 0.6 \\
(4.1,5.6)\end{array}$ & 0.51 & 0.82 \\
\hline
\end{tabular}

a Findings from multivariate analysis of variance

" Increased from initial to follow-up for all groups

\section{DISCUSSION}

This is the first investigation to examine the safety and effectiveness of a perturbation-based neuromuscular training program on dynamic balance in physically active adolescent females at risk of ACL injury. These results suggest that participation in the perturbation-based NM training program was safe but had no significant effect on YBT performance in either healthy or ACL-injured adolescent females. In healthy participants, a significant improvement in hip abduction strength was noted following completion of the perturbation-based NM training program; however, the improvement was not clinically significant. All other 
Table 5. Proprioception and flexibility measurements for the healthy subjects, reported as mean \pm SD, (95\% confidence interval).

\begin{tabular}{|c|c|c|c|c|c|c|}
\hline & \multicolumn{2}{|c|}{ Control $(n=12)$} & \multicolumn{2}{|c|}{ Perturbation $(n=12)$} & \multicolumn{2}{|c|}{$p$-value ${ }^{a}$} \\
\hline & Initial & Follow-up & Initial & Follow-up & Time & Time $x$ Group \\
\hline Knee Proprioception $\left(\Delta^{0}\right)$ & $\begin{array}{l}2.8 \pm 1.2 \\
(2.0,3.6)\end{array}$ & $\begin{array}{l}3.3 \pm 2.3 \\
(1.8,4.8)\end{array}$ & $\begin{array}{l}2.8 \pm 1.7 \\
(1.7,3.9)\end{array}$ & $\begin{array}{l}3.3 \pm 3.2 \\
(1.3,5.3)\end{array}$ & 0.54 & 0.98 \\
\hline Hip Flexibility (cm) & $\begin{array}{c}5.6 \pm 15.6 \\
(-4.3,15.5)\end{array}$ & $\begin{array}{c}7.1 \pm 15.5 \\
(-2.7,16.9)\end{array}$ & $\begin{array}{c}8.2 \pm 7.1 \\
(3.7,12.7)\end{array}$ & $\begin{array}{c}7.6 \pm 9.1 \\
(1.8,13.4)\end{array}$ & 0.61 & 0.25 \\
\hline Ankle Flexibility (cm) & $\begin{array}{l}11.3 \pm 3.5 \\
(9.1,13.5)\end{array}$ & $\begin{array}{l}11.0 \pm 3.5 \\
(8.8,13.2)\end{array}$ & $\begin{array}{l}11.8 \pm 3.2 \\
(9.8,13.8)\end{array}$ & $\begin{array}{c}12.3 \pm 3.2 \\
(10.3,14.3)\end{array}$ & 0.85 & 0.43 \\
\hline
\end{tabular}

a Findings from multivariate analysis of variance

Table 6. Proprioception and flexibility measurements for the ACL-injured subjects, reported as mean \pm SD, $(95 \%$ confidence interval).

\begin{tabular}{|c|c|c|c|c|c|c|}
\hline & \multicolumn{2}{|c|}{ Control $(n=5)$} & \multicolumn{2}{|c|}{ Perturbation $(n=5)$} & \multicolumn{2}{|c|}{$p$-value ${ }^{a}$} \\
\hline & Initial & Follow-up & Initial & Follow-up & Time & Time $\times$ Group \\
\hline Knee Proprioception $\left(\Delta^{0}\right)$ & $\begin{array}{l}3.6 \pm 2.1 \\
(1.0,6.2)\end{array}$ & $\begin{array}{l}2.1 \pm 1.5 \\
(0.2,4.0)\end{array}$ & $\begin{array}{c}1.9 \pm 1.8 \\
(-0.3,4.1)\end{array}$ & $\begin{array}{c}3.3 \pm 4.8 \\
(-2.7,9.3)\end{array}$ & 0.95 & 0.23 \\
\hline Hip Flexibility (cm) & $\begin{array}{c}1.1 \pm 9.8 \\
(-11.1,13.3)\end{array}$ & $\begin{array}{c}4.1 \pm 7.6 \\
(-5.3,13.5)\end{array}$ & $\begin{array}{c}9.5 \pm 9.4 \\
(-2.2,21.2)\end{array}$ & $\begin{array}{l}10.0 \pm 6.6 \\
(1.8,18.2)\end{array}$ & 0.31 & 0.44 \\
\hline Ankle Flexibility (cm) & $\begin{array}{l}13.4 \pm 3.3 \\
(5.2,21.6)\end{array}$ & $\begin{array}{l}13.3 \pm 4.1 \\
(8.2,18.4)\end{array}$ & $\begin{array}{c}9.4 \pm 1.8 \\
(7.2,11.6)\end{array}$ & $\begin{array}{c}9.8 \pm 1.8 \\
(7.6,12.0)\end{array}$ & 0.51 & 0.33 \\
\hline
\end{tabular}

a Findings from multivariate analysis of variance

measures of lower extremity strength, proprioception and flexibility were unaffected by completion of the training regime. The hypothesis that completion of a perturbationbased NM exercise program would improve YBT scoring, as well as lower extremity physical measures such as strength, proprioception and flexibility was not supported. While results suggest that the perturbation-based NM regime can be safely completed by both healthy and ACL-injured adolescent females, the results call into question the ability of the exercise program to successfully improve dynamic balance or other physical attributes believed to influence ACL-injury rates in this at-risk adolescent population.

The results of the current investigation address a gap in the current literature regarding the safety and effectiveness of perturbation-based NM training in at-risk adolescent females who regularly participate in recreational sporting activities. Previous research has established that YBT performance scores are significantly influenced by the sample population's age, 59,62,63 sex, ${ }^{58,64-67}$ sport involvement, ${ }^{64,65}$ and level of competitiveness. ${ }^{68-70}$ Beyond this, published studies on perturbation-based NM training have focused on a physically active adult population. ${ }^{31-38}$ The demographic and anthropometric data showed that the study sample was comprised of physically active females who participated in a variety of recreational sporting activities, have normal body weight and physical stature, and had reached or were approaching physical maturity. The participants were representative of an athletic adolescent female population at-risk for sustaining an ACL injury. ${ }^{1,4,5}$ As such, the authors' believe the results are generalizable to a repre- sentative population.

Previous investigations targeting physically active adult populations have demonstrated the effectiveness of perturbation-based NM training programs. ${ }^{31-38}$ A quadricepsdominant muscular activation pattern (demonstrated in physically active healthy adult females) has been suggested as one variable that may contribute to a higher risk of ACL injury in female athletes. ${ }^{35}$ Perturbation training has been used to eliminate an imbalance between quadriceps and hamstring performance in adult females and thus may be beneficial as an ACL injury prevention program for this demographic. ${ }^{35,36}$ Females with ACL-deficient knee also demonstrate improved gait and coordination after participating in a perturbation-based NM training program. ${ }^{31-34,37,38}$ Although these results are encouraging for ACL injury prevention and rehabilitation in an adult population, differences in lower extremity biomechanics observed during adolescence may place teenage females at greater risk of ACL injury. A recent meta-analysis reported an age-related association between the outcomes of neuromuscular training and the risk of ACL injury, and highlighted the value of neuromuscular training in female athletes under 18 years of age. ${ }^{18}$ This investigation was necessary to determine if the positive effects of perturbation-based NM training demonstrated in an adult population would also be observed in adolescent females at risk of ACL injury. ${ }^{1,4,5,71}$

As all subjects randomized to the training group were able to complete the program without any incidence of knee joint pain, swelling or instability the current data suggest 
that the perturbation-based training was safe. However, the data indicated that completion of the training program had no significant effect on the YBT reach distances of this adolescent female population. Previous studies reported improvements in YBT scores after healthy youth athletes completed NM training. ${ }^{21-23}$ Vitale et al. evaluated an eight-week program focused on core stability, plyometric and body-weight strengthening exercises ${ }^{21}$; two other studies assessed a four-week ${ }^{22}$ or 10 -week ${ }^{23}$ FIFA $11+$ Kids program which included seven activities: a running game, two jumping exercises, a balance/coordination task, two exercises targeting body stability and an exercise to improve falling technique. Recent meta-analyses suggest that combining plyometric and balance exercises may maximize effectiveness of preventive NM programs for healthy adolescent females. ${ }^{26,29,72}$ The present study used a perturbation-based NM program in isolation so both the preventive effects in healthy subjects and the rehabilitative effects in ACL-injured subjects could be assessed. The current results suggest that perturbation training alone did not affect dynamic balance. Notably, plyometric exercises used in other NM programs may not be safe or practical for ACLinjured subjects. ${ }^{73}$ Failla et al. found that the addition of a preoperative rehabilitation program that combined perturbation and strength training resulted in greater functional outcomes and return-to-sport rates two years after ACL reconstruction in an active adult population. ${ }^{13}$ Additionally, an investigation by Capin et al. concluded that there were no added benefits to including perturbation-based exercises to a post-operative RTS training program that incorporated strengthening, agility and plyometrics among young female athletes after ACL reconstruction. ${ }^{74}$ Thus, further investigations of perturbation-based training regimes with various parameters (such as longer duration or increased training intensity) and alternative forms of NM training that combine perturbation training with other exercises that are safe for ACL-injured adolescent females (such as resistance training, cardiovascular conditioning, core strengthening and gait re-education), are still necessary to improve prevention and rehabilitation programs for those at-risk.

\section{LIMITATIONS}

It is important to acknowledge that the current study had several limitations. First, this study utilized a YBT testing protocol that was established for use in an adult population. The typical YBT protocol in adults involves four training trials and three test trials to report a reach distance as the average of the three test trials. ${ }^{41}$ The few studies that have investigated YBT in an adolescent population have reported significant variations in the testing protocol. ${ }^{21-23,43} \mathrm{~A}$ recent study of the YBT in an adolescent male population noted a diminished reliability in adolescent athletes compared to adults and recommended that six practice trials and three test trials should be performed to increase the reliability of adolescent YBT assessments. ${ }^{61}$ Dynamic body changes that occur during the process of puberty may affect results and should to be accounted for to create a standardized YBT protocol specifically for the adolescent population. A second limitation is that the a priori analysis indicated that 22 subjects would provide adequate power to assess dynamic balance. ${ }^{58,59}$ Time and funding limits for study completion, as well as the strict age, gender, and activity-level inclusion criteria for participants in the ACL-injured group meant that recruitment was limited to only an exploratory group of 10 subjects. Having said this, the authors believe it was important to include this limited data set because pre-surgical data that is specific to an ACL-injured adolescent female population is lacking in the literature. Finally, the data collection methods focussed exclusively on quantitative outcome measures; however, many subjects commented on how participation in the perturbation-based NM training regime lead to subjective improvements in confidence levels when performing the follow-up testing and enhanced their ability to complete activities of daily living such as riding a bike or participating in physical education classes. The inclusion of subjective or psychological assessment tools would have expanded the analysis and allowed examination of how participation in the perturbation-based NM training program may have influenced participant's confidence, self-esteem, and overall quality of life.

\section{CONCLUSION}

The goal of this study was to investigate the safety and effectiveness of a perturbation-based NM training program for improving dynamic balance in healthy and ACL-injured adolescent females. The results suggest that the perturbation training program is safe but has no significant effect on YBT performance in either the healthy or ACL-injured adolescent female participants. All measures of lower extremity strength, knee proprioception and flexibility of the hip and ankle joints were unaffected by the training program. Future research should examine whether perturbation-based NM training has a positive effect when combined with other forms of training currently used for ACL injury prevention or pre-operative rehabilitation in an at-risk population of adolescent female who regularly participate in sport.

\section{CONFLICTS OF INTEREST}

The Authors declare that there is no conflict of interest

Submitted: December 21, 2020 CDT, Accepted: March 18, 2021 CDT 


\section{REFERENCES}

1. Sanders TL, Maradit Kremers H, Bryan AJ, et al. Incidence of anterior cruciate ligament tears and reconstruction: a 21-year population-based study. Am J Sports Med. 2016;44(6):1502-1507. doi:10.1177/0363 $\underline{546516629944}$

2. Gianotti SM, Marshall SW, Hume PA, Bunt L. Incidence of anterior cruciate ligament injury and other knee ligament injuries: a national populationbased study. J Sci Med Sport. 2009;12(6):622-627. do i:10.1016/j.jsams.2008.07.005

3. Silvers HJ, Mandelbaum BR. Prevention of anterior cruciate ligament injury in the female athlete. $\mathrm{Br} \mathrm{J}$ Sports Med. 2007;41(Suppl 1):i52-59. doi:10.1136/bjs $\underline{\mathrm{m} .2007 .037200}$

4. Gornitzky AL, Lott A, Yellin JL, Fabricant PD, Lawrence JT, Ganley TJ. Sport-specific yearly risk and incidence of anterior cruciate ligament tears in high school athletes: a systematic review and metaanalysis. Am J Sports Med. 2016;44(10):2716-2723. do i: $10.1177 / 0363546515617742$

5. Stanley LE, Kerr ZY, Dompier TP, Padua DA. Sex differences in the incidence of anterior cruciate ligament, medial collateral ligament, and meniscal injuries in collegiate and high school sports: 2009-2010 Through 2013-2014. Am J Sports Med. 2016;44(6):1565-1572. doi:10.1177/036354651663092 7

6. Marx RG, Jones EC, Angel M, Wickiewicz TL, Warren RF. Beliefs and attitudes of members of the American Academy of Orthopaedic Surgeons regarding the treatment of anterior cruciate ligament injury. Arthrosc. 2003;19(7):762-770.

7. McRae SM, Chahal J, Leiter JR, Marx RG, Macdonald PB. Survey study of members of the Canadian Orthopaedic Association on the natural history and treatment of anterior cruciate ligament injury. Clin J Sport Med. 2011;21(3):249-258. doi:10.1097/JSM.0b01 $\underline{\text { 3e318219a649 }}$

8. Ramski DE, Kanj WW, Franklin CC, Baldwin KD, Ganley TJ. Anterior cruciate ligament tears in children and adolescents: a meta-analysis of nonoperative versus operative treatment. Am J Sports Med. 2014;42(11):2769-2776. doi:10.1177/036354651 $\underline{3510889}$

9. Mirza F, Mai DD, Kirkley A, Fowler PJ, Amendola A. Management of injuries to the anterior cruciate ligament: results of a survey of orthopaedic surgeons in Canada. Clin J Sport Med. 2000;10(2):85-88.
10. Peeler J, Leiter J, MacDonald P. Accuracy and reliability of anterior cruciate ligament clinical examination in a multidisciplinary sports medicine setting. Clin J Sport Med. 2010;20(2):80-85.

11. Eitzen I, Moksnes H, Snyder-Mackler L, Risberg MA. A progressive 5-week exercise therapy program leads to significant improvement in knee function early after anterior cruciate ligament injury. J Orthop Sports Phys Ther. 2010;40(11):705-721. doi:10.2519/jo spt.2010.3345

12. Alshewaier S, Yeowell G, Fatoye F. The effectiveness of pre-operative exercise physiotherapy rehabilitation on the outcomes of treatment following anterior cruciate ligament injury: a systematic review. Clin Rehabil. 2017;31(1):34-44. do $\mathrm{i}: 10.1177 / 0269215516628617$

13. Failla MJ, Logerstedt DS, Grindem H, et al. Does extended preoperative rehabilitation influence outcomes 2 years after ACL reconstruction? Am J Sports Med. 2016;44(10):2608-2614. doi:10.1177/0363 $\underline{546516652594}$

14. Swart E, Redler L, Fabricant PD, Mandelbaum BR, Ahmad CS, Wang YC. Prevention and screening programs for anterior cruciate ligament injuries in young athletes. J Bone Joint Surg Am. 2014;96(9):705-711. doi:10.2106/JBJS.M.00560

15. Hewett TE, Lindenfeld TN, Riccobene JV, Noyes FR. The effect of neuromuscular training on the incidence of knee injury in female athletes: a prospective study. Am J Sports Med. 1999;27(6):699-706.

16. Gilchrist J, Mandelbaum BR, Melancon H, et al. A randomized controlled trial to prevent noncontact anterior cruciate ligament injury in female collegiate soccer players. Am J Sports Med. 2008;36(8):1476-1483. doi:10.1177/036354650831818 8

17. Gagnier JJ, Morgenstern H, Chess L. Interventions designed to prevent anterior cruciate ligament injuries in adolescents and adults: a systematic review and meta-analysis. Am J Sports Med. 2013;41(8):1952-1962. doi:10.1177/036354651245822 $\underline{7}$

18. Myer GD, Sugimoto D, Thomas S, Hewett TE. The influence of age on the effectiveness of neuromuscular training to reduce anterior cruciate ligament injury in female athletes: a meta-analysis. Am J Sports Med. 2013;41(1):203-215. doi:10.1177/036 3546512460637 
19. DiStefano LJ, Padua DA, Blackburn JT, Garrett WE, Guskiewicz KM, Marshall SW. Integrated injury prevention program improves balance and vertical jump height in children. J Strength Cond Res. 2010;24(2):332-342.

20. Myer GD, Ford KR, Palumbo JP, Hewett TE. Neuromuscular training improves performance and lower-extremity biomechanics in female athletes. $J$ Strength Cond Res. 2005;19(1):51-60. doi:10.1519/136 $\underline{43.1}$

21. Vitale JA, La Torre A, Banfi G, Bonato M. Effects of an 8-wk body-weight neuromuscular training on dynamic balance and vertical jump performances in elite junior skiing athletes: A randomized controlled trial. J Strength Cond Res. 2018;32(4):911-920.

22. Pomares-Noguera C, Ayala F, Robles-Palazón FJ, et al. Training effects of the FIFA 11+ Kids on physical performance in youth football players: a randomized control trial. Front Pediatr. 2018;6. doi:10.3389/fped.2 $\underline{018.00040}$

23. Rössler R, Donath L, Bizzini M, Faude O. A new injury prevention programme for children's football FIFA 11+ Kids - can improve motor performance: a cluster-randomised controlled trial. J Sports Sci. 2016;34(6):549-556. doi:10.1080/02640414.2015.1099 $\underline{715}$

24. Benis R, Bonato M, La Torre A. Elite female basketball players' body-weight neuromuscular training and performance on the Y-balance Test. $J$ Athl Train. 51(9):688-695.

25. Michaelidis M, Koumantakis GA. Effects of knee injury primary prevention programs on anterior cruciate ligament injury rates in female athletes in different sports: A systematic review. Phys Ther Sport. 2014;15(3):200-210. doi:10.1016/i.ptsp.2013.12.002

26. Sugimoto D, Myer GD, Barber Foss KD, Hewett TE. Specific exercise effects of preventive neuromuscular training intervention on anterior cruciate ligament injury risk reduction in young females: meta-analysis and subgroup analysis. Br J Sports Med. 2015;49(5):282-289. doi:10.1136/bjsports-2014-09346 1

27. Emery CA, Roy T-O, Whittaker JL, Nettel-Aguirre $A$, van Mechelen W. Neuromuscular training injury prevention strategies in youth sport: a systematic review and meta-analysis. Br J Sports Med. 2015;49(13):865-870. doi:10.1136/bjsports-2015-0946 $\underline{39}$
28. Noyes FR, Barber-Westin SD. Neuromuscular retraining intervention programs: do they reduce noncontact anterior cruciate ligament injury rates in adolescent female athletes? Arthrosc J Arthrosc Relat Surg. 2014;30(2):245-255. doi:10.1016/j.arthro.2013.1 0.009

29. Rössler R, Donath L, Verhagen E, Junge A, Schweizer T, Faude O. Exercise-based injury prevention in child and adolescent sport: a systematic review and meta-analysis. Sports $\mathrm{Med}$. 2014;44(12):1733-1748. doi:10.1007/s40279-014-023 4-2

30. Fitzgerald GK, Axe MJ, Snyder-Mackler L. Proposed practice guidelines for non-operative anterior cruciate ligament rehabilitation of physically active individuals. J Orthop Sports Phys Ther. 2000;30(4):194-203.

31. Fitzgerald GK, Axe MJ, Snyder-Mackler L. The efficacy of perturbation training in nonoperative anterior cruciate ligament rehabilitation programs for physically active individuals. Phys Ther. 2000;80(2):128-140.

32. Chmielewski TL, Hurd WJ, Rudolph KS, Axe MJ, Snyder-Mackler L. Perturbation training improves knee kinematics and reduces muscle co-contraction after complete unilateral anterior cruciate ligament rupture. Phys Ther. 2005;85(8):740-749.

33. Di Stasi SL, Snyder-Mackler L. The effects of neuromuscular training on the gait patterns of ACLdeficient men and women. Clin Biomech. 2012;27(4):360-365. doi:10.1016/j.clinbiomech.201 1.10 .008

34. Hartigan E, Axe MJ, Snyder-Mackler L. Perturbation training prior to ACL reconstruction improves gait asymmetries in non-copers. J Orthop Res. 2009;27(6):724-729. doi:10.1002/jor.20754

35. Letafatkar A, Rajabi R, Tekamejani EE, Minoonejad $\mathrm{H}$. Effects of perturbation training on knee flexion angle and quadriceps to hamstring cocontraction of female athletes with quadriceps dominance deficit: pre-post intervention study. Knee. 2015;22(3):230-236. doi:10.1016/j.knee.2015.02.001

36. Hurd WJ, Chmielewski TL, Snyder-Mackler L. Perturbation-enhanced neuromuscular training alters muscle activity in female athletes. Knee Surg Sports Traumatol Arthrosc. 2006;14(1):60-69. doi:10.1007/s0 0167-005-0624-y

37. Di Stasi SL, Hartigan EH, Snyder-Mackler L. Unilateral stance strategies of athletes with ACL deficiency. J Appl Biomech. 2012;28(4):374. 
38. Chmielewski TL, Rudolph KS, Snyder-Mackler L. Development of dynamic knee stability after acute ACL injury. J Electromyogr Kinesiol. 2002;12(4):267-274

39. Daniel DM, Stone ML, Dobson BE, Fithian DC, Rossman DJ, Kaufman KR. Fate of the ACL-injured patient: a prospective outcome study. Am J Sports Med. 1994;22(5):632-644. doi:10.1177/036354659402 200511

40. Davies PL, Rose JD. Motor skills of typically developing adolescents: awkwardness or improvement? Phys Occup Ther Pediatr. 2000;20(1):19-42.

41. Plisky PJ, Gorman PP, Butler RJ, Kiesel KB, Underwood FB, Elkins B. The reliability of an instrumented device for measuring components of the star excursion balance test. N Am J Sports Phys Ther. 2009;4(2):92-99.

42. Bulow A, Anderson JE, Leiter JR, MacDonald P, Peeler J. The modified star excursion balance and Ybalance tests differ when assessing physically active healthy adolescent females. Int J Sports Phys Ther. 2019;14(2):192-203.

43. Gribble PA, Kelly SE, Refshauge KM, Hiller CE. Interrater reliability of the star excursion balance test. J Athl Train. 2013;48(5):621-626. doi:10.4085/10 62-6050-48.3.03

44. Herbert L, Maltais D, Lepage C, Saulnier J, Crete $\mathrm{M}$, Perron M. Isometric muscle strength in youth assessed by hand-held dynamometry: a feasibility, reliability and validity study. Pediatr Phys Ther. 2011;23:289-299.

45. Stark T, Walker B, Phillips JK, Fejer R, Beck R. Hand-held dynamometry correlation with the gold standard isokinetic dynamometry: a systematic review. PM\&R. 2011;3(5):472-479. doi:10.1016/j.pmr j.2010.10.025

46. Eek MN, Kroksmark A-K, Beckung E. Isometric muscle torque in children 5 to 15 years of age: normative data. Arch Phys Med Rehabil. 2006;87(8):1091-1099. doi:10.1016/j.apmr.2006.05.01 $\underline{2}$

47. Stillman B, McMeeken JM. The role of weightbearing in the clinical assessment of knee joint position sense. Aust J Physiother. 2001;47:247-253.

48. Mir SM, Hadian M-R, Talebian S, Nasseri N. Functional assessment of knee joint position sense following anterior cruciate ligament reconstruction. Br J Sports Med. 2008;42(4):300-303. doi:10.1136/bjs $\underline{\mathrm{m} .2007 .044875}$
49. Arockiaraj J, Korula RJ, Oommen AT, et al. Proprioceptive changes in the contralateral knee joint following anterior cruciate injury. Bone Jt J. 2013;95(2):188-191.

50. Hoch MC, Staton GS, McKeon PO. Dorsiflexion range of motion significantly influences dynamic balance. J Sci Med Sport. 2011;14(1):90-92. doi:10.101 6/j.jsams.2010.08.001

51. Ayala F, Sainz de Baranda P, De Ste Croix M, Santonja F. Reproducibility and criterion-related validity of the sit and reach test and toe touch test for estimating hamstring flexibility in recreationally active young adults. Phys Ther Sport. 2012;13(4):219-226. doi:10.1016/j.ptsp.2011.11.001

52. Gajdosik RL, Bohannon RW. Clinical measurement of range of motion review of goniometry emphasizing reliability and validity. Phys Ther.

1987;67(12):1867-1872.

53. Grindem H, Granan LP, Risberg MA, Engebretsen L, Snyder-Mackler L, Eitzen I. How does a combined preoperative and postoperative rehabilitation programme influence the outcome of ACL reconstruction 2 years after surgery? A comparison between patients in the Delaware-Oslo ACL Cohort and the Norwegian National Knee Ligament Registry. Br J Sports Med. 2015;49(6):385-389. doi:10.1136/bjsp orts-2014-093891

54. Shaarani SR, O’Hare C, Quinn A, Moyna N, Moran $\mathrm{R}$, O'Byrne JM. Effect of prehabilitation on the outcome of anterior cruciate ligament reconstruction. Am J Sports Med. 2013;41(9):2117-2127. doi:10.1177/0 $\underline{363546513493594}$

55. Risberg MA, Holm I, Myklebust G, Engebretsen L. Neuromuscular training versus strength training during first 6 months after anterior cruciate ligament reconstruction: a randomized clinical trial. Phys Ther. 2007;87(6):737-750. doi:10.2522/ptj.20060041

56. Risberg MA, Holm I. The long-term effect of 2 postoperative rehabilitation programs after anterior cruciate ligament reconstruction: a randomized controlled clinical trial with 2 years of follow-up. Am J Sports Med. 2009;37(10):1958-1966. doi:10.1177/0363 $\underline{546509335196}$

57. Hartigan EH, Axe MJ, Snyder-Mackler L. Time-line for noncopers to pass return-to-sports criteria after anterior cruciate ligament reconstruction. J Orthop Sports Phys Ther. 2010;40(3):141-154. doi:10.2519/jos pt.2010.3168

58. Faigenbaum AD, Myer GD, Fernandez IP, et al. Feasibility and reliability of dynamic postural control measures in children in first through fifth grades. Int $J$ Sports Phys Ther. 2014;9(2):140-148. 
59. Munro AG, Herrington LC. Between-session reliability of the star excursion balance test. Phys Ther Sport. 2010;11(4):128-132. doi:10.1016/j.ptsp.2010.0 7.002

60. Zult T, Gokeler A, van Raay JJAM, Brouwer RW, Zijdewind I, Hortobágyi T. An anterior cruciate ligament injury does not affect the neuromuscular function of the non-injured leg except for dynamic balance and voluntary quadriceps activation. Knee Surg Sports Traumatol Arthrosc. 2017;25(1):177-183. $\underline{\mathrm{d}}$ oi:10.1007/s00167-016-4335-3

61. Linek P, Sikora D, Wolny T, Saulicz E. Reliability and number of trials of Y Balance Test in adolescent athletes. Musculoskelet Sci Pract. 2017;31:72-75. doi:1 0.1016/j.msksp.2017.03.011

62. Hudson C, Garrison JC, Pollard K. Y-balance normative data for female collegiate volleyball players. Phys Ther Sport. 2016;22:61-65. doi:10.1016/ j.ptsp.2016.05.009

63. van Lieshout R, Reijneveld EA, van den Berg SM, et al. Reproducibility of the modified sart excursion balance test composite and specific reach direction scores. Int J Sports Phys Ther. 2016;11(3):356.

64. Plisky PJ, Rauh MJ, Kaminski TW, Underwood FB. Star Excursion Balance Test as a predictor of lower extremity injury in high school basketball players. $J$ Orthop Sports Phys Ther. 2006;36(12):911-919.

65. Filipa A, Byrnes R, Paterno MV, Myer GD, Hewett TE. Neuromuscular training improves performance on the star excursion balance test in young female athletes. J Orthop Sports Phys Ther.

2010;40(9):551-558. doi:10.2519/jospt.2010.3325

66. Brophy RH, Staples JR, Motley J, Blalock R, StegerMay K, Halstead M. Young females exhibit decreased coronal plane postural stability compared to young males. HSS J. 2016;12(1):26-31. doi:10.1007/s11420-0 $\underline{15-9458-4}$
67. Holden S, Boreham C, Doherty C, Wang D, Delahunt E. A longitudinal investigation into the progression of dynamic postural stability performance in adolescents. Gait Posture. 2016;48:171-176. doi:10.1016/j.gaitpost.2016.04.019

68. Butler RJ, Southers C, Gorman PP, Kiesel KB, Plisky PJ. Differences in soccer players' dynamic balance across levels of competition. J Athl Train. 2012;47(6):616-620. doi:10.4085/1062-6050-47.5.14

69. Smith CA, Chimera NJ, Warren M. Association of Y-balance test reach asymmetry and injury in division I athletes. Med Sci Sports Exerc. 2015;47(1):136-141. $\underline{\mathrm{d}}$ oi:10.1249/MSS.0000000000000380

70. Engquist KD, Smith CA, Chimera NJ, Warren M. Performance comparison of student-athletes and general college students on the functional movement screen and the Y-balance test. J Strength Cond Res. 2015;29(8):2296-2303.

71. Bencke J, Aagaard P, Zebis MK. Muscle activation during ACL injury risk movements in young female athletes: a narrative review. Front Physiol. 2018;9. do i:10.3389/fphys.2018.00445

72. Padua DA, DiStefano LJ, Hewett TE, et al. National Athletic Trainers' Association position statement: prevention of anterior cruciate ligament injury. J Athl Train. 2018;53(1):5-19. doi:10.4085/1062-6050-99-16

73. Hartigan EH, Lynch AD, Logerstedt DS, Chmielewski TL, Snyder-Mackler L. Kinesiophobia after anterior cruciate ligament rupture and reconstruction: noncopers versus potential copers. J Orthop Sports Phys Ther. 2013;43(11):821-832. doi:1 $\underline{0.2519 / j o s p t .2013 .4514}$

74. Capin JJ, Failla M, Zarzycki R, et al. Superior 2-year functional outcomes among young female athletes after ACL reconstruction in 10 return-tosport training sessions: comparison of ACL-SPORTS randomized controlled trial with Delaware-Oslo and MOON cohorts. Orthop J Sports Med. 2019;7(8). doi:1 $\underline{0.1177 / 2325967119861311}$ 


\begin{tabular}{|c|c|c|c|}
\hline \multicolumn{4}{|c|}{$\begin{array}{l}\text { Treatment Goals: } \\
\text { - Expose athlete to perturbations in all directions } \\
\text { - Elicit an appropriate muscular response to applied perturbations (no rigid co-contraction) } \\
\text { Movement Application: } \\
\text { - Inform patient of direction \& timing } \\
\text { - Slow force; Low magnitude } \\
\text { - Each set } 1 \mathrm{~min}\end{array}$} \\
\hline Session & Rocker Board & Roller Board/Platform & Roller Board \\
\hline 1 & $\begin{array}{l}\text { - } \text { Bilateral stance } \\
\text { - } 2 \text { sets anterior/poste- } \\
\text { rior } \\
\text { - } 2 \text { sets medial/lateral }\end{array}$ & $\begin{array}{l}\text { - } 2 \text { sets with injured limb on roller board, anterior/posterior } \\
\text { - } 2 \text { sets with uninjured limb on roller board, anterior/poste- } \\
\text { rior } \\
\text { - } 2 \text { sets with injured limb on roller board, medial/lateral } \\
\text { - } 2 \text { sets with uninjured limb on roller board, medial/lateral }\end{array}$ & $\begin{array}{l}\text { - } \text { Bilateral stance } \\
\text { - } 2 \text { sets anterior/poste- } \\
\text { rior } \\
\text { - } 2 \text { sets medial/lateral }\end{array}$ \\
\hline 2 & $\begin{array}{l}\text { - } \quad \text { Unilateral stance } \\
\text { - } 2 \text { sets anterior/poste- } \\
\text { rior } \\
\text { - } 2 \text { sets medial/lateral }\end{array}$ & $\begin{array}{l}\text { - } 2 \text { sets with injured limb on roller board, anterior/posterior } \\
\text { - } 2 \text { sets with uninjured limb on roller board, anterior/poste- } \\
\text { rior } \\
\text { - } 2 \text { sets with injured limb on roller board, medial/lateral } \\
\text { - } 2 \text { sets with uninjured limb on roller board, medial/lateral }\end{array}$ & $\begin{array}{l}\text { - Unilateral stance } \\
\text { - } 2 \text { sets anterior/poste- } \\
\text { rior } \\
\text { - } 2 \text { sets medial/lateral }\end{array}$ \\
\hline 3 & $\begin{array}{l}\text { - Unilateral stance } \\
\text { - } 3 \text { sets anterior/poste- } \\
\text { rior } \\
\text { - } 3 \text { sets medial/lateral }\end{array}$ & $\begin{array}{l}\text { - } 3 \text { sets with injured limb on roller board, anterior/posterior } \\
\text { - } 3 \text { sets with uninjured limb on roller board, anterior/poste- } \\
\text { rior } \\
\text { - } 3 \text { sets with injured limb on roller board, medial/lateral } \\
\text { - } 3 \text { sets with uninjured limb on roller board, medial/lateral }\end{array}$ & $\begin{array}{l}\text { - Unilateral stance } \\
\text { - } 3 \text { sets anterior/poste- } \\
\text { rior } \\
\text { - } 3 \text { sets medial/lateral }\end{array}$ \\
\hline 4 & $\begin{array}{l}\text { - Unilateral stance } \\
\text { - } 3 \text { sets anterior/poste- } \\
\text { rior } \\
\text { - } 3 \text { sets medial/lateral }\end{array}$ & $\begin{array}{l}\text { - } 3 \text { sets with injured limb on roller board, anterior/posterior } \\
\text { - } 3 \text { sets with uninjured limb on roller board, anterior/poste- } \\
\text { rior } \\
\text { - } 3 \text { sets with injured limb on roller board, medial/lateral } \\
\text { - } 3 \text { sets with uninjured limb on roller board, medial/lateral }\end{array}$ & $\begin{array}{l}\text { - Unilateral stance } \\
\text { - } 3 \text { sets anterior/poste- } \\
\text { rior } \\
\text { - } 3 \text { sets medial/lateral }\end{array}$ \\
\hline
\end{tabular}




\begin{tabular}{|c|c|c|c|}
\hline \multicolumn{4}{|c|}{$\begin{array}{l}\text { Treatment Goals: } \\
\text { - Add light sport-specific activity during perturbation tec } \\
\text { Movement Applove athlete accuracy in matching muscle response } \\
\text { • Unexpected forces } \\
\text { - Rapid, increasing magnitude force application } \\
\text { - Short delay between subsequent force applications } \\
\text { - Begin combining directional movement of roller board }\end{array}$} \\
\hline Session & Rocker Board & Roller Board/Platform & Roller Board \\
\hline 5 & $\begin{array}{l}\text { - Unilateral stance } \\
\text { - } 2 \text { sets anterior/poste- } \\
\text { rior } \\
\text { - } 2 \text { sets medial/lateral }\end{array}$ & $\begin{array}{l}\text { - } 1 \text { set with injured limb on roller board, anterior/posterior } \\
\text { - } 1 \text { set with uninjured limb on roller board, anterior/poste- } \\
\text { rior } \\
\text { - } 1 \text { set with injured limb on roller board, medial/lateral } \\
\text { - } 1 \text { set with uninjured limb on roller board, medial/lateral } \\
\text { - } 2 \text { sets with injured limb on roller board, combination } \\
\text { movement } \\
\text { - } 2 \text { sets with uninjured limb on roller board, combination } \\
\text { movement }\end{array}$ & $\begin{array}{l}\text { - Unilateral stance } \\
\text { - } 1 \text { set anterior/posterior } \\
\text { - } 1 \text { set medial/lateral } \\
\text { - } 2 \text { sets combination move- } \\
\text { ments }\end{array}$ \\
\hline 6 & $\begin{array}{l}\text { - Unilateral stance } \\
\text { - } 2 \text { sets anterior/poste- } \\
\text { rior } \\
\text { - } 2 \text { sets medial/lateral }\end{array}$ & $\begin{array}{l}\text { - } 1 \text { set with injured limb on roller board, anterior/posterior } \\
\text { - } 1 \text { set with uninjured limb on roller board, anterior/poste- } \\
\text { rior } \\
\text { - } 1 \text { set with injured limb on roller board, medial/lateral } \\
\text { - } 1 \text { set with uninjured limb on roller board, medial/lateral } \\
\text { - } 2 \text { sets with injured limb on roller board, combination } \\
\text { movement } \\
\text { - } 2 \text { sets with uninjured limb on roller board, combination } \\
\text { movement }\end{array}$ & $\begin{array}{l}\text { - Unilateral stance } \\
\text { - } 1 \text { set anterior/posterior } \\
\text { - } 1 \text { set medial/lateral } \\
\text { - } 2 \text { sets combination move- } \\
\text { ments }\end{array}$ \\
\hline 7 & $\begin{array}{l}\text { - Unilateral stance } \\
\text { - } 2 \text { sets anterior/poste- } \\
\text { rior } \\
\text { - } 2 \text { sets medial/lateral }\end{array}$ & $\begin{array}{l}\text { - } 1 \text { set with injured limb on roller board, anterior/posterior } \\
\text { - } 1 \text { set with uninjured limb on roller board, anterior/poste- } \\
\text { rior } \\
\text { - } 1 \text { set with injured limb on roller board, medial/lateral } \\
\text { - } 1 \text { set with uninjured limb on roller board, medial/lateral } \\
\text { - } 3 \text { sets with injured limb on roller board, combination } \\
\text { movement } \\
\text { - } 3 \text { sets with uninjured limb on roller board, combination } \\
\text { movement }\end{array}$ & $\begin{array}{l}\text { - Unilateral stance } \\
\text { - } 1 \text { set anterior/posterior } \\
\text { - } 1 \text { set medial/lateral } \\
\text { - } 3 \text { sets combination move- } \\
\text { ments }\end{array}$ \\
\hline
\end{tabular}




\begin{tabular}{|c|c|c|c|}
\hline \multicolumn{4}{|c|}{$\begin{array}{l}\text { Treatment Goals: } \\
\qquad \text { Increase difficulty of perturbation by usi } \\
\bullet \text { Obtain accurate, selective muscular resp } \\
\text { Movement Application: } \\
- \text { Increased magnitude force application } \\
\bullet \text { Random direction movements } \\
\text { - Little to no delay between applications } \\
\text { - Distraction via ball toss }\end{array}$} \\
\hline Session & Rocker Board & Roller Board/Platform & Roller Board \\
\hline 8 & $\begin{array}{l}\text { - Unilateral stance } \\
\text { - } 1 \text { set random (linear } \\
\text { foot) } \\
\text { - } 2 \text { sets random (diag- } \\
\text { onal foot) }\end{array}$ & $\begin{array}{l}\text { - } 2 \text { sets with injured limb on roller board, combination } \\
\text { movement } \\
\text { - } 2 \text { sets with uninjured limb on roller board, combination } \\
\text { movement } \\
\text { - } 1 \text { set with injured limb on roller board, combination } \\
\text { movement (no delay) } \\
\text { - } 1 \text { set with uninjured limb on roller board, combination } \\
\text { movement (no delay) }\end{array}$ & $\begin{array}{l}\text { - Unilateral stance } \\
\text { - } 2 \text { sets combination move- } \\
\text { ments } \\
\text { - } 1 \text { set combination movements } \\
\text { (no delay) }\end{array}$ \\
\hline 9 & $\begin{array}{l}\text { - Unilateral stance } \\
\text { - } 1 \text { set random (linear } \\
\text { foot) } \\
\text { - } 2 \text { sets random (diag- } \\
\text { onal foot) }\end{array}$ & $\begin{array}{l}\text { - } 3 \text { sets with injured limb on roller board, combination } \\
\text { movement (no delay) } \\
\text { - } 3 \text { sets with uninjured limb on roller board, combination } \\
\text { movement (no delay) }\end{array}$ & $\begin{array}{l}\text { - Unilateral stance } \\
\text { - } 3 \text { sets combination move- } \\
\text { ments (no delay) }\end{array}$ \\
\hline 10 & $\begin{array}{l}\text { - Unilateral stance } \\
\text { - } 1 \text { set random (linear } \\
\text { foot) } \\
\text { - } 2 \text { sets random (diag- } \\
\text { onal foot) }\end{array}$ & $\begin{array}{l}\text { - } 3 \text { sets with injured limb on roller board, combination } \\
\text { movement (no delay) } \\
\text { - } 3 \text { sets with uninjured limb on roller board, combination } \\
\text { movement (no delay) }\end{array}$ & $\begin{array}{l}\text { - Unilateral stance } \\
\text { - } 3 \text { sets combination move- } \\
\text { ments (no delay) }\end{array}$ \\
\hline
\end{tabular}

